\title{
Supportive organisational cultures and their effect on male civil engineers
}

Valerie Francis (Lecturer, Construction Management, Faculty of Architecture, Building and Planning, University of Melbourne, Australia)

\section{ABSTRACT}

Substantial changes, not only in the demographic composition of the Australian workforce, but also in the roles and expectations of men and women, have led to organisational and employee attempts to reconcile work and non-work demands. Research suggests that when work-family balance practices are introduced they can greatly enhance organisational efficiency. However factors embedded in the organisational culture can undermine these policies rendering them ineffective. This quantitative study examined the relationship between the perceptions of a supportive work culture and some work and non-work experiences of Australian male civil engineers. The research investigated the prevalence of organisational values supportive of work-life balance as well as the level of workfamily conflict perceived by those engineers. This paper reports some initial results of the study. These indicate that male civil engineers experience moderate levels of work-family conflict but do not perceive their organisations to be very supportive of employee needs to balance work and personal life. However those that reported a supportive work environment also reported higher levels of organisational commitment, greater job and life satisfaction as well as lower level of work-family conflict and lower intentions to quit. The implications of the findings for organisations employing civil engineers are discussed.

Keywords: organisational culture, civil engineers, men, job satisfaction, life satisfaction.

\section{INTRODUCTION}

Many job and organisational factors found to impact negatively on family and non-work life are pertinent to civil engineers. These include long and irregular work hours, schedule inflexibility, high job demands, job insecurity and frequent relocation (Greenhaus and Beutell, 1985; Hughes, Galinsky and Morris, 1992; Williams and Alliger, 1994, Parasuraman, Purohit, Godshalk and Beutell, 1996; Shaffer, Harrison, Gilley and Luk, 2001).

The increase in interest in work-life balance issues has led some researchers to explore the experiences of civil engineers, and other employees of the construction industry, at the workfamily interface (Mills and Francis, 1998; Lingard and Sublet, 2002). Lingard (2004), in a study investigating burnout in civil engineers, found family variables to be important sources of burnout in parents and dual income couples. Lingard and Francis (in press) found site-based construction employees to be particularly vulnerable to high levels of work-family conflict and burnout than employees who worked in the head or regional office.
This paper provides some initial findings of a research project investigating civil engineers and reports specifically on the work and non-work experiences of male civil engineers. In particular, the research investigated how supportive civil engineers perceive their workplaces to be towards work-family issues. While providing organisational work-family policies is important, it is imperative to recognise that these will have very little worth, and employees will not feel comfortable utilising them, unless their value is embedded strongly within the culture of the organisation (Lewis, 2001).

As women have been the prime instigators of work-family policies being adopted by organisations (Bourke, 2000), much of the research in this field has focused on women and on female dominated professions. The rationale for the research, a discussion on organisational culture and its effect on the workfamily interface are presented, along with details of the research method adopted and initial key findings. The perceived levels of work-family conflict and supportiveness of the organisational culture to work-family balance was investigated. In particular, the impact of a supportive culture on: work-family conflict, job satisfaction, organisational commitment, turnover intent, life satisfaction and well-being were examined.

\section{BACKGROUND}

Substantial changes, not only in the demographic composition of the Australian workforce, but also in the roles and expectations of men and women, have led to organisational and employee attempts to reconcile work and non-work demands.

More women are in the workforce, reflecting rising educational levels, changing societal attitudes, declining birth rates and increased childbearing age (Bourke, 2000). As a consequence, the number of dual income couples overall has increased and in $59 \%$ of Australian two-parent families, both parents are in paid employment (Australian Bureau of Statistics (ABS), 1998).

There has also been a substantial shift in the expectation of fathers' involvement in parenting. An Australian study by Russell, Barclay, Edgecombe, Donovan, Habib, Callaghan, and Pawson (1999) found $57 \%$ of fathers, on being asked to report on the major barrier to them becoming involved as a father, indicated work related factors $(30 \%$ noted work load and work commitments, $16 \%$ time pressures and $11 \%$ having to earn an income). A twelve-year study by Amato and Booth (1997) provides strong evidence of the influence of fathers on their children's development and well-being. Russell and his colleagues (1999) in a survey of fathers found these men believed the greatest influence fathers can have on their child's well-being and adjustment was "being accessible to children" 
and $68 \%$ wished they could spend more time with their children. It was therefore surprising that they also found little difference in the time fathers actually spent with their children in 1998 compared to 1983.

Russell et al (1999) also found a large portion of working fathers experienced high levels of stress and the report strongly supported the development of strategies specifically for men to help them better balance their work and family responsibilities. Like many working mothers, fathers who try and fulfill both family ("masculine" and "feminine") roles of "provider" and "nurturer" often experience higher levels of stress and greater levels of work-family conflict as the roles are inherently incompatible (Cooper, 2000). However, as employers generally assume their female employees, with dependants, will take advantage of available work-family policies and make career adjustments to care for children (Glezer and Wolcott, 2000) men face criticism if they do not demonstrate "ideal" masculine characteristics. This in turn can affect workplace perceptions of them possessing "ideal" worker characteristics (loyalty, etc.) (Cooper, 2000).

While the majority of Australian men work full-time, women's employment status is highly affected by familial factors (i.e. age of youngest child, number of children etc.) and it is considered that many Australian families have traditionally attempted to balance their work and non-work responsibilities through the lower level of paid work undertaken by women (Glezer and Wolcott, 2000). However many young women, particularly professionals, are returning to full-time work after maternity leave because of financial necessity, personal desire and/or to reduce negative career consequences. (Bourke, 2000).

Recent changes from institutional aged care to home and community-based care now means that filial responsibility rests more heavily with family members. Currently, $70 \%$ of all providers of personal care and home help for the aged, terminally ill or disabled persons are also in the Australian work force (ABS, 1994). In addition, increasing portions of employees face the responsibility of dependent children and filial care simultaneously or sequentially due to the increasing trend by younger couples to delay parenting.

While the number of workers with dependant care responsibilities has never before been so high, managers and professionals are experiencing increasing performance pressures, and hours spent at the workplace are increasing. Perhaps unsurprisingly, a recent report prepared by the Australian Bureau of Statistics (ABS) found, that in dual income couples, $56 \%$ of all fathers reported that they always/often felt rushed or pressed for time (ABS, 1999).

\section{WHY ORGANISATIONS NEED TO CONSIDER THE FAMILY RESPONSIBILITIES OF THEIR EMPLOYEES}

Arguments for providing a workplace that is supportive of employees' lives outside work are numerous, but can be broken down into two main categories: legal requirements and organisational performance. Legislation that stems from a social justice base, presents a strong motive for companies to address the concerns of their employees with family responsibilities. In, 1990, Australia ratified International Labor Organisation (ILO) Convention 156, dealing with workers with family responsibilities, consequently legislative and industrial reforms have flowed through, prohibiting dismissal on the basis of family responsibility as well as improving working conditions (Bourke, 2000).

Allen (2001) found that decreased levels of work-life strain results in increased job satisfaction, decreased employee turnover and improved levels of organisational commitment. In a study by Grover and Crooker (1995) employees in companies with family-supportive benefits had higher levels of affective commitment (emotional attachment) to the organisation and expressed lower turnover intentions, regardless of whether the employee individually benefited from the policy. They postulated that work-family benefits had a positive influence on employees' attachment to the organisation because they signified corporate concerns for employee well-being. In addition, affective commitment has been associated with higher productivity (Meyer, Paunonen, Gellatly, Goffin and Jackson, 1989) and a more positive work attitude (Allen and Meyer, 1996).

Organisational variables such as schedule flexibility, supervisor support and time overload (Thomas and Ganster, 1995;

Parasuraman et al., 1996), and family-related variables such as parenting overload, spousal and familial support, and family distress (Parasuraman et al., 1996; Frone, Yardley and Markel, 1997) have been found to directly influence family relationships, work-family conflict and intent to leave the workplace (Crouter, Bumpus, Head and McHale, 2001; Rothausen, 1994). Support from supervisor, spouse and family, have been shown to reduce work-family conflict through their impact on role overload and work distress (Frone et al, 1997).

\section{THE IMPORTANCE OF A SUPPORTIVE ORGANISATIONAL CULTURE}

Research has shown even when family-friendly policies have been established factors embedded in the organisational culture undermine these policies, rendering them ineffective (Lewis, 2001). Denison defined organisational culture as "the deep structure of organisations, which is rooted in values, beliefs, and assumptions held by organisational members." (Denison, 1996, p624). Attitudes still exist in many work places that promote the image of the "ideal" worker as a person who is able and willing to put their work first.

Bailyn (1997) outlined three characteristics identifiable in a family-friendly work culture: flexible work scheduling, flexible work processes and an understanding by organisational leadership that family needs are important. Research has shown that supervisors play a key role in the effectiveness of both the implementation and utilisation of work-family policies and that employees' whose supervisor supported their efforts to balance work and family were less likely to experience workfamily conflict (Thomas and Ganster, 1995). Thompson, Beauvais and Lyness (1999, p394) expanded the understanding of work-family culture to include the "shared assumptions, beliefs, and values regarding the extent to which 
an organisation supports the values and integration of employees' work and family lives." They consider a negative work-family culture to have at least three components; organisational time demands or expectations that employees prioritise work over family, negative career consequences associated with utilising work-family benefits, and lack of managerial support and sensitivity to employees' family responsibilities.

The traditional model of work, which remains the basis of many management practices, and thus deeply embedded in many organisational cultures, assumes that an employees' work domain is totally isolated from their family domain. This ethos has been challenged in some industries. However, as this process of change has typically been driven by female employees and their managers (Bourke, 2000), it would perhaps not be surprising that reform within the engineering profession is not as evident, given the low numbers of women employed (Yates, Agnew, Kryger and Palmer, 2001). Fielden, Davidson, Gale and Davey (2000) suggested that in the construction industry, a lack of compliance with cultural norms, such as refusing to undertake long hours, could adversely affect the promotion prospects of employees and even their job security. One study undertaken by Burke (2000) found that male managers reporting higher levels of organisational support also reported greater joy in work, and lower levels of job stress and intention to quit. As employees strongly influence workplace culture, understanding male perceptions in a male dominated environment is a useful addition to research in the work-family field.

Consequently, this research has two main aims. Firstly, the research will determine the prevalence of supportive organisational values and the level of work-family conflict perceived by male civil engineers. Secondly, the research will examine the relationship between organisational values perceived to be supportive of work-family balance and; workfamily conflict, job satisfaction, organisational commitment, turnover intent, life satisfaction and mental health.

In particular, it is hypothesised that the engineering workplace will not be perceived by its employees to be one that is very sympathetic of employees' needs to balance their work and family lives. In addition those employees who do perceive their workplaces to be supportive will also have higher levels of job and life satisfaction, improved levels of organisational commitment, less work-family conflict, lower turnover intent and fewer mental health problems.

\section{METHOD}

Sample

The sample was recruited with the help of an Australian professional organisation for engineers. Data were collected using a self-administered questionnaire sent to 500 male civil engineers aged between 25 to 55 years. Questionnaires were completed anonymously and returned in a reply paid envelope. Of these, 93 participants returned completed questionnaires, and taking into account surveys that could not be delivered the return rate was $19.3 \%$. Because of financial restrictions reminder letters were not issued and given the length of the survey and the random selection of the sample the response rate of nearly $20 \%$, while low, was considered sufficient. Upon analysis, two participants were excluded as they had either failed to complete the majority of the questionnaire, or wrote that they did not identify themselves as civil engineers. The final sample consisted of 91 male civil engineers, $82 \%$ who were partnered and $71 \%$ who had children. The sample had an average age of 39.8 years $(\underline{\mathrm{SD}}=7.74)$, and an average working week of 48.5 hours $(\underline{S D}=9.14)$. Further information on the sample can be found in Table 1. 


\begin{tabular}{|c|c|c|c|c|c|}
\hline & $\mathbf{N}$ & $\%$ & & $\mathbf{N}$ & $\%$ \\
\hline Age & & & \multicolumn{3}{|c|}{ No of employees in organisation } \\
\hline 26 - 30 years & 13 & 14.4 & $1-19$ & 16 & 17.6 \\
\hline 31 - 35 years & 16 & 17.8 & $20-49$ & 10 & 11.0 \\
\hline 36 - 40 years & 17 & 18.9 & $50-199$ & 10 & 11.0 \\
\hline $41-45$ years & 17 & 18.9 & $200-999$ & 26 & 28.6 \\
\hline $46-50$ years & 19 & 21.1 & 1000 or more & 29 & 31.9 \\
\hline \multirow[t]{2}{*}{$51-55$ years } & 8 & 8.9 & & & \\
\hline & & & Sector of employment & & \\
\hline Family Structure & & & Public Sector & 29 & 31.9 \\
\hline $\begin{array}{l}\text { Couple with dependent } \\
\text { children }\end{array}$ & 47 & 52.8 & Private Sector & 62 & 68.1 \\
\hline Couple with non- & 10 & 11.2 & Work hours per week & & \\
\hline dependent children & & & 20 hours or less & 1 & 1.1 \\
\hline Single parent & 6 & 6.7 & $21-35$ hours & 2 & 2.2 \\
\hline Couple without children & 16 & 18.0 & $36-45$ hours & 38 & 42.2 \\
\hline \multirow[t]{2}{*}{ Single person } & 10 & 11.2 & $46-55$ hours & 36 & 40.0 \\
\hline & & & 56 hours or more & 13 & 14.4 \\
\hline \multicolumn{6}{|l|}{ Years since graduation } \\
\hline 5 years or less & 11 & 12.4 & Tenure & & \\
\hline $6-10$ years & 15 & 16.9 & 2 or less years & 45 & 51.1 \\
\hline $11-15$ years & 16 & 18.0 & $3-5$ years & 26 & 29.5 \\
\hline $16-20$ years & 15 & 16.9 & $6-10$ years & 14 & 15.9 \\
\hline 21 years or more & 32 & 36.0 & $11-15$ years & 3 & 3.4 \\
\hline
\end{tabular}

Table 1: Demographic Characteristics of the Sample.

\section{Measures}

The survey consisted of questions concerning demographic, organisational, professional, and familial factors. All measures had been used in previous studies were adopted because of their known high levels of internal consistency and the ones relating to this paper are discussed below.

Work family culture was measured via a 20 -item scale (Thompson et al, 1999) that investigated three main areas: managerial support, negative career consequences, and organisational time demands. The alpha reliability for each subconstruct was $.78, .76$ and .73 respectively. Respondents were asked to decide to what extent the statements characterised their current organisation using a scale ranging from strongly disagree (1) to strongly agree (7). It included items such as "In the event of a conflict, managers are understanding when employees have to put their family first." and "To turn down a promotion or transfer for family-related reasons will seriously hurt one's career progress in this organisation (reversed scored)" and "Employees are often expected to take work home at night and/or on weekends (reversed scored)".
Inter-role conflict was measured via a ten-item, 7-point scale ranging from 1 (for strongly disagree) to 7 (for strongly agree), developed by Netemeyer, Boles and McMurrian (1996) with the sub-constructs of work to family conflict, and family to work conflict. The alpha reliability for each sub-construct was .91 and .87 respectively. Items for each subscale were summed and high scores indicated a higher level of conflict. Sample items were "The demands of my work interfere with my home and family life" and "The demands of my family or spouse/partner interfere with work-related activities".

Organisational commitment was measured using a six-items scale, ranging from 1 (for strongly disagree) to 7 (for strongly agree), adapted from the original 18-item scale of Meyer, Allen and Smith (1993). Two items (with the highest loading) from each of three sub-constructs of affective, continuance and normative commitment were selected. This is in accordance with previous studies that have required shorter scales due to time restrictions. Due to the small number of items in each subconstruct mean inter-item correlations were calculated (as recommended by Briggs and Cheek, 1986) and found to be .41 . Sample items include "This organisation has a great deal of 
personal meaning for me", "I feel that I have too few options to consider leaving this organisation (reverse coded)" and "This organisation deserves my loyalty". Organisational commitment was calculated using the mean value of all sub-constructs.

Job satisfaction was measured via a 14-item scale developed by Hackman and Oldham (1975). The scale tapped into specific facets of the participant's employment such as their satisfaction with their pay, job security, social, supervisory and growth. Respondents were asked how satisfied or dissatisfied they were with different aspects of their job (1 for extremely dissatisfied to 7 for extremely satisfied). Sample items are "The amount of support and guidance I receive from my supervisor", "The degree to which I am fairly paid for what I contribute to this organisation", and "The amount of independent thought and action I can exercise in my job". The alpha reliability for each sub-construct was above .8 except for social, which was .6 . Overall job satisfaction was calculated using the mean value of all sub-scales. Colleague support was measured in a similar manner to other facets of job satisfaction but using a single item to determine participants' satisfaction with the level of support they receive from their colleagues.

Work load was measured using a 3-item scale adopted in a study by House, McMichael, Wells, Kaplan and Landerman (1979) that had been used in previous studies. Respondents were asked how frequently they felt, from never (0) to very often (5), certain conditions within their job relating to speed, difficulty and time restraints. A higher score is indicative of a higher work load. The alpha reliability for the sample was .87 .
Turnover intentions were measured via the two items on a scale ranging from 1 (for strongly disagree) to 7 (for strongly agree). A sample item was "I often think about quitting". A higher score reflected a higher likelihood of a person leaving their job. The alpha reliability for the sample was .80 .

Life satisfaction, which assesses an individual's perceptions regarding the quality of their life in general, was measured using a five-item scale ranging from 1 (for strongly disagree) to 7 (for strongly agree) developed by Diener, Emmons, Larsen, \& Griffin (1985). A sample item from this scale is "I am satisfied with my life." The scale's alpha reliability for the sample was .89 .

Well-being or mental health was measured using the General Health Questionnaire (GHQ-12) that was developed to detect minor psychiatric illnesses in the community (Goldberg, 1972). The general scoring method was deemed most appropriate for the sample being studied so scores of 0 to 3 were assigned to item responses, then summed to give a final score (ranging from 0 to 36) - a higher score is indicative of lower mental health. The alpha reliability was .89 .

\section{RESULTS}

Data were analysed using an SPSS for Windows package (version 11) and the results are presented in Tables 2 and 3. The results provided in Table 2 indicate that civil engineers perceive their organisations to be only very slightly supportive of employees' family needs with a mean item value of 4.45 (where neutral was 4 and slightly agree was 5 ). Work-family conflict had a mean value of 22.37 that represents a mean item value of 4.47. This indicates that, in general, civil engineers feel they have a moderate level of work-family conflict with the mean score for WFC being above the mid point mark.

\begin{tabular}{lccccc}
\hline & $\begin{array}{c}\text { No of } \\
\text { items }\end{array}$ & $\begin{array}{c}\text { Possible } \\
\text { Range }\end{array}$ & $\begin{array}{c}\text { Mean value } \\
\text { (scale) }\end{array}$ & $\begin{array}{c}\text { Std deviation } \\
\text { (scale) }\end{array}$ & $\begin{array}{c}\text { Mean value } \\
\text { (item) }\end{array}$ \\
\hline Work family culture (overall) & 20 & $20-140$ & 89.51 & 8.37 & 4.48 \\
\hline Managerial support & 11 & $11-77$ & 51.01 & 8.37 & 4.64 \\
\hline Career consequences & 5 & $5-35$ & 21.97 & 5.16 & 4.39 \\
\hline Organisational time demands & 4 & $4-28$ & 16.53 & 4.91 & 4.13 \\
\hline
\end{tabular}

Table 2: Work Family Culture. 
Table 3 presents the correlations between the measures of work family culture and measures of inter-role conflict, organisational experiences and life experiences. As expected male civil engineers who reported organisational values that supported employees' non-work life had statistically significant lower levels of work-family conflict. In other words the conflict that can transfer to the home environment because of demands at work were less in more supportive work environments. In addition male civil engineers reporting organisational values, which were supportive of employees' work and family, also reported higher levels of organisational commitment, great levels of job satisfaction and lower intentions to leave their organisations. On a personal level engineers who reported a more supportive culture also reported higher life satisfaction and higher levels of mental health or well-being.

\begin{tabular}{|c|c|c|c|c|c|}
\hline & \multirow[b]{2}{*}{ Mean } & \multirow{2}{*}{$\begin{array}{c}\text { Std. } \\
\text { Deviation }\end{array}$} & \multicolumn{3}{|c|}{ Work Family Culture } \\
\hline & & & $\begin{array}{c}\text { Managerial } \\
\text { Support }\end{array}$ & $\begin{array}{c}\text { Career } \\
\text { Consequences }\end{array}$ & $\begin{array}{l}\text { Organisational } \\
\text { Time Demands }\end{array}$ \\
\hline \multicolumn{6}{|l|}{ Inter-role Conflict } \\
\hline Work Family Conflict & 22.37 & 6.84 & $-.358\left(^{* \star}\right)$ & $-.229\left(^{*}\right)$ & $-.444\left({ }^{* *}\right)$ \\
\hline Family Work Conflict & 14.83 & 6.33 & -0.093 & $-.364\left({ }^{* *}\right)$ & -0.013 \\
\hline \multicolumn{6}{|l|}{ Organisational Experiences } \\
\hline Work Hours per week & 48.52 & 9.14 & -.144 & -.145 & $-.369\left({ }^{* *}\right)$ \\
\hline Organisational Commitment & 4.04 & 1.07 & $\left..295^{(*}\right)$ & 0.138 & $.295\left(^{* *}\right)$ \\
\hline Overall Job Satisfaction & 5.12 & .86 & $.401\left(^{* *}\right)$ & $.417\left({ }^{* \star}\right)$ & $.230\left(^{*}\right)$ \\
\hline Pay Satisfaction & 4.40 & 1.54 & $\left..352^{(* *}\right)$ & $.218\left(^{*}\right)$ & $\left..289^{(*}\right)$ \\
\hline Security Satisfaction & 5.36 & 1.29 & $.268\left(^{\star}\right)$ & $.272\left(^{*}\right)$ & $.225\left(^{*}\right)$ \\
\hline Social Satisfaction & 5.22 & .89 & $\left..302^{(* *}\right)$ & $.309\left(^{* *}\right)$ & 0.105 \\
\hline Supervisory Satisfaction & 5.04 & 1.28 & $.218\left(^{*}\right)$ & $.319\left(^{* *}\right)$ & 0.141 \\
\hline Growth Satisfaction & 5.35 & 1.08 & $.329\left(^{* *}\right)$ & $.353(* *)$ & 0.135 \\
\hline Colleague Support & 5.22 & 1.27 & $.260\left(^{*}\right)$ & $\left..3611^{* *}\right)$ & $.244\left(^{*}\right)$ \\
\hline Intention to Turnover & 3.43 & 1.80 & $-.408\left(^{* *}\right)$ & $-.305\left(^{* *}\right)$ & $-.419(* *)$ \\
\hline Work Load & 8.71 & 2.22 & -0.087 & -0.064 & $-.236\left(^{*}\right)$ \\
\hline \multicolumn{6}{|c|}{ Life Satisfaction and Well-being } \\
\hline Satisfaction with Life & 21.54 & 6.70 & $.366\left(^{* *}\right)$ & $.326(* *)$ & $\left..316^{(* *}\right)$ \\
\hline Mental Health & 12.24 & 5.66 & $-.331\left(^{\star *}\right)$ & $-.311\left({ }^{* *}\right)$ & $-.284(* *)$ \\
\hline
\end{tabular}

Table 3: Correlations of Work Family Culture and other variables.

** Correlation is significant at the 0.01 level (2-tailed).

* Correlation is significant at the 0.05 level (2-tailed).

As expected there is also statistically significant correlations between work-family culture and satisfaction with supervisor indicative of a supportive workplace, and work hours and organisational time demands. It should be noted that many of the measures of organisational experiences, satisfactions and well-being are themselves correlated (i.e. life satisfaction and mental health, life satisfaction and job satisfaction).

\section{DISCUSSION}

The research found that male civil engineers do experience moderate levels of work-family conflict and in general work in organisations that they do not perceive to be very supportive of employees' need to balance work and family demands. The profession appears to suffer a "cultural lag" with traditional values being considered the norm and consequently the ones rewarded (e.g. long work hours, full-time working). In this study $96.7 \%$ of men worked $37.5 \mathrm{hr}$ per week or more and $47.8 \%$ worked more than 50 hrs per week. However while $53.4 \%$ were happy with the hours they worked $45.5 \%$ would prefer to work less hours per week. The study did not, however, support a preference for part-time work options. This may be related to the samples low level of satisfaction with their current pay and benefits, compared to other facets of job satisfaction measured. Being professionals they are typically not paid for any overtime carried out and their average working hours per week is substantial more than a standard $37.5 \mathrm{hr}$ week. Perhaps the desire to work less, but not part-time, is indicative of a desire to reduce work hours while maintaining a reasonable salary level. A report by Russell and Bowman (2000) found Australian men reporting an increased preference for working less hours and working part-time work. 
The paper also examined the relationship between perceptions of a supportive work family culture and organisational commitment, job satisfaction, work load, turnover intent as well as life satisfaction and mental health. While the importance of implementing work-family policies such as part-time work options, flexible work arrangements (work locations, work times etc), as well as dependant care support schemes is clear, it is also important to recognise that these policies will have very little worth unless their value is strongly embedded in the culture of the organization (Lewis, 2001; Thompson et al, 1999). For instance as Russell et al (2000) argue, if the underlying cultural assumption is that an employee's presence at work is seen as an indicator of their commitment and contribution, employees put their careers at risk in terms of poor performance evaluations or promotions, if they participate in work-family programs that make them less visible at work (e.g. working from home). Hence the provision of benefits delivered through human resources policies is not sufficient in itself. A workplace culture must exist within which employees feel comfortable taking advantage of alternative workplace policies.

The data indicates strong correlations between a supportive work culture with higher levels of organisational commitment and job satisfaction. Affective organisational commitment has been associated with higher productivity (Meyer et al, 1989) and a more positive work attitude. The data from this study shows that if an organisation is perceived to be unsupportive of work-family balance then turnover intent increases. These variables were strongly correlated. The availability and perceived quality of employment alternatives is recognised to be a key factor in job commitment and turnover. Staff turnover has specific expenses in terms of costs relating to retraining, recruitment and lost productivity and the civil engineering profession must be careful that its members do not leave it in order to pursue careers that provide greater benefits. Already civil engineering is dropping in career appeal and in the 1999 edition of the Jobs Rated Almanac, civil engineering fell from $18^{\text {th }}$ to $70^{\text {th }}$ position in expressed job preference.

At a personal level those reporting a supportive culture also reported higher levels of life satisfaction and better levels of mental health. So from an occupational health perspective as well as from an organisational performance viewpoint the data provides evidence of the benefits of a supportive work culture.

\section{CONCLUSIONS}

The purpose of this study was to determine the prevalence of work-family conflict and supportive organisational values experienced by male civil engineers and the interrelationship between a supportive culture and some work and non-work experiences. The study found that while male civil engineers do have moderate levels of work-family conflict in general, those that report higher levels also perceive their work place to be not as supportive of employees' family needs. In addition strong correlations were found between supportive organisational values and lower intention to quit; higher levels of organisational commitment, job and life satisfaction; and lower levels of mental health issues.
In order to achieve a supportive culture, change must be driven from the top down and sensitivity training for middle managers and supervisors may also be required (Thomas and Ganster, 1995, Thompson et al, 1999, Lewis, 2001). While the benefits to employees with dependants are clear, one could wonder whether employees without partners or dependants feel disadvantaged. However Grover and Crooker (1995) found employees, regardless of whether they individually benefited from a work-family policy or not, had higher levels of affective commitment to their organisation and postulated that the provision of benefits had a positive influence on all employees.

It is important that both men and women receive research consideration in the work-family area. Stereotyped expectations of career and personal priorities can render the combination of a fulfilling family life and a successful career impossible. Finding benefits for men from supportive organisational values may encourage more firms to examine their values on these issues. Considering the low percentage of female engineers, and the fact that women have been the prime instigators of change in these policy areas, finding advantages for male engineers may have a greater impact on the engineering profession than attempting to create change from an equity perspective.

For organisations to succeed they must be cognisant of the needs of workers with family responsibilities and indeed changes in legislation as well as the need to recruit, and retain, committed and satisfied employees provide some very strong motives. However the change needed in engineering may not come easily. Indeed however accepting of change they may be at the start of their career, male entrants inadvertently reinforce current attitudes and practices by emulating the behaviour of the managers who influenced their own career development (Dainty et al., 2000).

It should be noted that while this study has revealed associations between work and family variables, being a crosssectional study it is limited in its ability to determine causal relationships. This paper has reported initial findings only and further analysis of the full dataset will be carried out to investigate the effect of gender, family structure, presence of dependants and organisational size, to develop an understanding of the relationship between various organisational and familial factors. In particular, investigation of the presence of work-life benefits currently available to civil engineers and their relationship to organisational and personal factors will be made. It is hoped that this work will inform companies on these issues so they can develop policies that are suitable for their different employees.

\section{REFERENCES}

Australian Bureau of Statistics. (1994) Focus on Families: Work and Family Responsibilities, Cat No 4422.0, Canberra.

Australian Government Printing Services.

Australian Bureau of Statistics (1998) Labour Force, Australia, Cat No 6203.0, May, Canberra. Australian Government Printing Services. 
Australian Bureau of Statistics (1999) Balancing Work and Caring Responsibilities Cat No 4903.6, Canberra. Australian Government Printing Services.

Allen, N J and Meyer, J P (1996) Affective, continuance, and normative commitment to the organisation: An examination of construct validity. Journal of Vocational Behavior, 49,252-276.

Allen, T. D., (2001), Family-supportive work environments: The role of organizational perceptions, Journal of Vocational Behavior, 58, 414-435.

Bailyn, L (1997) The impact of corporate culture on work-family integration. In S Parasuraman and J H Greenhaus (Eds) Integrating work and family: Challenges and choices for a changing world. Pp209-219, Westport, Quorum Books.

Bourke, J (2000) Corporate Women, Children and Workplace culture: the integration of flexible work practices into the Legal and Financial professions. Studies in organisational analysis and innovation Monograph Number 15, Industrial Relations Research Centre, UNSW, Sydney.

Briggs, S R and Cheek, J M (1986) The role of factor analysis in the development and evaluation of personality scales. Journal of Personality, 54, 106-148.

Cooper, M (2000) Being the "Go-to Guy": Fatherhood, Masculinity, and the organization of work in Silicon Valley. Qualitative Sociology, 23, 379-405.

Crouter, A C, Bumpus, M F, Head, M R and McHale, S M (2001) Implications of overwork and overload for the quality of men's family relationships. Journal of Marriage and Family. 63(2), 404416.

Dainty, A R J, Neale, R H and Bagilhole, B M (2000)

Comparison of Men's and Women's Careers in U. K

Construction Industry. Journal of Professional Issues in

Engineering Education and Practice. July 2000, ASCE.

Denison, D R (1996) What is the difference between organisational culture and organisational climate? A native's point of view on a decade of paradigm wars. Academy of Management Review, 21,619-654.

Diener, E, Emmons, R A, Larson, R J and Griffin, S (1985) The satisfaction with life scale. Journal of Personality Assessment, 49, 71-75.

Fielden, S L, Davidson, M J Gale, A W and Davey, C L (2000) Women in Construction: The Untapped Resource. Construction Management and Economics, 18, 113-121.

Frone, M R, Yardley, J K and Markel, K S (1997) Developing and testing an integrated model of the work-family interface. Journal of Vocational Behavior, 50,145-167.

Glezer H and Wolcott I (2000) Conflicting Commitments: Working mothers and fathers in Australia. In Hass L, Hwang P and Russell G (eds) Organizational Change and Gender Equity - International perspectives on parents at the workplace, Cal, Sage.

Goldberg, D P. (1972) The Detection of Psychiatric Illness by Questionnaire. Oxford University Press, Oxford.
Gutek, B A, Searle, S and Klepa, L (1991) Rational vs. gender role explanations for the work-family conflict. Journal of Applied Psychology, 76, 560-568.

Greenhaus, J H and Beutell, N J (1985) Sources of conflict between work and family roles. Academy of Management Review, 10, 76-88.

Grover, S L and Crooker, K J (1995) Who appreciates family responsive human resource policies: The impact of family friendly policies on the organisational attachment of parents and non parents. Personnel Psychology, 48, 271-288.

Hackman, J R and Oldham, G R. (1975) Development of the Job Diagnostic Survey. Journal of Applied Psychology, 60, 159170.

Hill, E., Hawkins, Al, Ferris, M., and Weitzman, M. (2001). Finding an extra day a week: The positive influence of perceived job flexibility on work and family life balance. Family Relations, 50, 49 - 58.

House, J., McMichael, A., Wells, J., Kaplan, B., \& Landerman, L., (1979). Occupational stress and health among factory workers. Journal of Health and Social Behavior, 20, 139 - 160.

Hughes, D, Galinsky, E and Morris, A (1992) The Effects of Job Characteristics on Marital Quality: Specifying Linking Mechanisms. Journal of Marriage and the Family, 54, 31-42.

Lewis S (2001) Restructuring workplace cultures: the ultimate work-family challenge. Women in Management Review, vol 16 , N1, pp21-29.

Lingard, H., (2004) Work and Family Sources of Burnout in the Australian Engineering Profession: Comparison of Respondents in Dual- and Single-Earner Couples, Parents, and Nonparents. Journal of Construction Engineering and Management, Vol. 130(2), pp. 290-298.

Lingard, $H$. and Francis, V. (in press) - The work-life experiences of office and site-based employees in the Australian construction industry, Construction Management and Economics, accepted $26^{\text {th }}$ April 2004.

Lingard, H. and Sublet, A., (2002) - The impact of job and organisational demands on marital and relationship quality among Australian civil engineers, Construction Management and Economics, 20: pp. 507-521.

Meyer, J P and Allen, N J and Smith, C A (1993) Commitment to organisations and occupations: Extension and test of a threecomponent conceptualization. Journal of Applied Psychology, $78,538-551$.

Meyer, J P, Paunonen, S V, Gellatly, I R, Goffin, R D and Jackson, D N (1989) Organisation commitment and job performance: It's the nature of the commitment that counts. Journal of Applied Psychology, 74, 152-156.

Mills J E and Francis V E (1998) "Are we losing out? - The case for flexible work arrangements", Australian Journal of Structural Engineering, Vol. 1(1), 29-34. 
Netemeyer, R G, Boles, J S and McMurrian, R. (1996)

Development and Validation of the Work-Family Conflict and

Family-Work Conflict Scales. Journal of Applied Psychology, 81, 400-410.

Parasuraman, S, Purohit, Y S, Godshalk, V M and Beutell, N J (1996) Work and family variables, entrepreneurial career success and psychological well-being. Journal of Vocational Behavior, 48, 275-300.

Rothausen, T J (1994) Job satisfaction and the parent worker: The role of flexibility and rewards. Journal of Vocational Behavior, 44, 317-336.

Russell, G, Barclay L, Edgecombe G, Donovan J, Habib G, Callaghan $\mathrm{H}$ and Pawson Q (1999) Fitting Fathers into Families: Men and the Fatherhood role in Contemporary Australia. Dept Family and Community Services, Commonwealth of Australia.

Russell, G and Bowman, L (2000) Work and Family: Current Thinking, Research and Practice. Dept Family and Community Services, Commonwealth of Australia.

Shaffer, M A, Harrison, D A, Gilley, K M and Luk, D M (2001) Struggling for balance amid turbulence on international assignments: Work-family conflict, support and commitment. Journal of Management, 27, 99-121.

Thomas, L T and Ganster, D C (1995) Impact of familysupportive variables on work-family conflict and strain: A control perspective. Journal of Applied Psychology, 80, 6-15.

Thompson, C S, Beauvais, L L and Lyness, K S (1999) When work- family benefits are not enough: The influence of workfamily culture on benefit utilization, organisational attachment, and work-family conflict. Journal of Vocational behavior, 54, 392-415.

Williams, K J and Alliger, G M (1994) Role Stressors, mood spillover, and perceptions of work-family conflict in employed parents. Academy of Management Review, 37, 837-868.

Yates, A, Agnew, J, Kryger, S and Palmer, M (2001) The Engineering Profession: A Statistical Overview 2001. Institution of Engineers, Australia, Canberra. 
